\title{
PERNAMBUCO À ESQUERDA? A FORÇA POLÍTICA DAS FAMÍLIAS ARRAES-CAMPOS NA ESFERA ESTADUAL
}

\author{
José Adilson Filho ${ }^{1}$
}

\begin{abstract}
RESUMO: Este artigo procura analisar histórica e sociologicamente a importância e a força politica das famílias Arraes e Campos no estado de Pernambuco, a partir de um olhar que busca enfatizar suas trajetórias, alianças, práticas, representações, ambiguidades e afinidades ideológicas na construção de uma hegemonia politica de base familiar. Trata-se, todavia, de duas famílias que na maior parte de suas histórias constituíram-se simbolicamente como um só corpo politico, cuja práxis se orientaria pelo viés ideológico de esquerda ou centro-esquerda. Portanto, buscamos descrever e interpretar alguns elementos que fizeram com que tais famílias fossem transformadas em atores singulares à cena politica estadual e nacional. Teórica e metodologicamente o texto se fundamenta nas contribuições interdisciplinares da Nova História Politica, cujo enfoque busca apreender as contradições e ambiguidades presentes nas trajetórias, práticas e representações dos sujeitos sociais em escala simultaneamente local, regional e nacional.
\end{abstract}

Palavras-chave: Famílias Arraes-Campos, Poder político, Pernambuco.

\section{IS PERNAMBUCO ON THE LEFT? THE POLITICAL FORCE OF THE ARRAES-CAMPOS FAMILIES AT THE STATE LEVEL}

\begin{abstract}
This article analyzes, from a historical and sociological view, the importance and the political strength of the Arraes and Campos families in the state of Pernambuco. We have worked with this issue in a perspective that endeavors to emphasize the trajectories, alliances, practices, representations, ambiguities and ideological affinities inherent the construction of a family-based political hegemony. Arraes and Campos are two families that, in most of their histories symbolically, are understood as one unit body whose praxis has been guided by the ideological inclination to the left or center-left. In this article, we attempt to describe and interpret some elements that made these families become singulars actors in the state and national political scene. Concerning the theoretical and methodological aspects, the text is based on the interdisciplinary contributions of the New Political History, whose focus seeks to grasp the contradictions and ambiguities present in the trajectories, practices, and representations of social subjects on a local, regional and national scale.
\end{abstract}

Key words: Arraes-Campos Families, Political Power, Pernambuco

\footnotetext{
${ }^{1}$ Mestre em História pela UFPE e Doutor em Sociologia pela UFPB. Atualmente é professor adjunto da Universidade Estadual da Paraíba (UEPB). E-mail: adilsonhistory@gmail.com
} 


\section{Introdução}

A história é um campo de saber epistemologicamente ambíguo, porque oscila entre a arte e a ciência, entre a imaginação criativa e o verossímil. E, mais ainda, por desejar construir diálogos entre sujeitos de tempos e espaços diferentes. Este olhar retrospectivo que reconstrói o passado e o articula ao presente, não apenas é indicio de sua ambiguidade, mas, principalmente, da complexidade que caracteriza o seu pensar e fazer.

A escrita da História ao mesmo tempo em que incorpora tradições, busca, incansavelmente, romper limites e convenções. Por conta desta sua natureza ambivalente, seus conhecimentos e estatuto serão sempre questionados por seus praticantes, admiradores e críticos. Conhecimento movediço cujo chão esconde enigmas e surpresas. Não seria diferente a um saber que pretende ser a narrativa da experiência humana através dos tempos. É por essa razão que ela se encontra cada vez mais mergulhada no desejo de perscrutar questões que até então estiveram fora de seu alcance.

Interpretar a experiência e a ação dos homens e das mulheres através das várias temporalidades torna o historiador um artesão do tempo, um sujeito cuja sensibilidade lhe permite observar e auscultar com relativa profundidade e poética os movimentos, as mudanças, as tensões, as alegrias e os sofrimentos de indivíduos e dos grupos sociais. Essa sensibilidade não o leva apenas a olhar e a falar de um tempo distante da sua existência. Tal qual um pássaro ele atravessa com seu voo as mais altas, baixas, remotas ou próximas paisagens temporais. Não importa sobre qual período histórico o historiador se debruçará, uma vez que sua investigação sempre estará apoiada num olhar retrospectivo, ou seja, num recuo temporal, a despeito do seu objeto lhe ser demasiadamente contemporâneo. Nesse sentido, os temas mais próximos e viscerais à sua experiência como ator social são também passíveis de uma análise histórica e não devem ser negligenciados ou simplesmente colocados como área exclusiva dos sociólogos, jornalistas, cientistas políticos e antropólogos. Até porque o historiador é por natureza um antropófago, isto é, alguém que não cessa de se alimentar das contribuições dos seus confrades das ciências sociais e humanas. 
Pensando com o poeta Carlos Drummond de Andrade diríamos que o tempo presente, os homens presentes e a vida presente ${ }^{2}$ são também a matéria do historiador e, não apenas aquilo que ficou ossificado num passado distante. Nosso artigo se inscreve dentro do que muitos historiadores chamam de História do Tempo Presente e História Imediata $^{3}$, pois tais abordagens se voltam a estudar temas que se confundem, virtualmente, com o tempo e o lugar vividos pelo pesquisador.

Desejamos, portanto, fazer uma análise histórica e sociológica sobre a trajetória politica das famílias Arraes/Campos - ambas fundamentais para compreendermos a força do espectro politico de base familiar no estado de Pernambuco. Atualmente elas exercem posições, funções e domínios privilegiados sobre a esfera pública estadual, com rebatimentos em nível nacional. E estão enlaçadas pelo parentesco e pelo poder. O sobrenome Arraes e os seus sentidos dele derivados estão inscritos na história e na memória social há pelos menos uns 70 anos, enquanto os Campos figuram a pouco mais de uma década no que se refere às tramas politicas. Sendo assim, temos duas famílias num só corpo politico.

\section{Miguel Arraes: Um politico e suas múltiplas histórias}

Hoje quando pensamos na figura politica de Eduardo Campos, ex-governador de Pernambuco - somos instados quase que automaticamente a relacioná-lo ao líder nacionalista Miguel Arraes de Alencar ${ }^{4}$. $\mathrm{O}$ mito do avô há muitos anos precede a do neto. Já que a sua trajetória começa em 1948, quando da sua participação como secretário da fazenda no governo de Barbosa Lima Sobrinho. Ele é, pois, um signo de uma das vertentes da cultura politica brasileira, processada entre as décadas de 1930 a 1960, cuja

\footnotetext{
${ }^{2}$ ANDRADE, Carlos Drummond de. Mãos dadas. In. Sentimento do Mundo. Cia das Letras: São Paulo, 2012.

${ }^{3}$ Sobre isso ver de CHAVEAU, A, TETART, Phillippe. (orgs.) Questões para o Presente. Bauru: Edusc, 2000.

${ }^{4}$ Nasceu em 15 de dezembro de 1916 no município de Araripe (CE) e morreu no Recife no dia 13 de agosto de 2005. Filho primogênito e único dos pequenos produtores rurais Maria Benigna Arraes e José Almino Alencar e Silva. Era formado em Direito pela antiga Faculdade de Direito do Recife e funcionário concursado do Instituto do Açucar e Álcool (IAA). Casou-se duas vezes. Com Célia de Sousa Leão, de tradicional família aristocrática pernambucana, teve oito filhos. Já com Maria Madaglena Fiuza Arraes de Alencar teve mais dois filhos.
} 
perspectiva politica-ideológica se ancorava num discurso nacionalista, anti-imperialista, desenvolvimentista, e popular.

Arraes teve sua história construída dentro destes marcos. Com o apoio de setores da elite burocrática do PSD, de trabalhistas do PTB e de algumas frações da burguesia local, além do engajamento do partido comunista brasileiro, sindicatos e de movimentos artísticos e populares, vencerá as eleições para prefeito do Recife, em 1959, e para governador do estado, em 1962. Contudo, seu mandato seria bruscamente interrompido devido ao golpe civil-militar de 1964, que lhe arrancou o poder e o jogou num exílio de quase quinze anos na Argélia. Com a Anistia, em 1979, retorna ao Brasil e depois se elegeu deputado federal pelo MDB nas eleições de 1982. A força do seu espectro politico, legitimado pelo carisma e força popular, porém, consubstanciado por alianças com setores conservadores da politica e da economia (a exemplo de famílias políticas tradicionais, industriais, banqueiros e usineiros) e segmentos do campo progressista e popular, seriam fundamentais para elegê-lo governador do estado por mais duas vezes (1986, 1994).

A ampla base político-social inscrita nas chamadas Frente do Recife e Frente Popular, responsável por suas maiores vitórias para prefeito e para governador por três vezes ajudará a polarizar ainda mais os embates entre os grupos e as classes sociais no estado. A novidade é que depois de sua experiência administrativa de base popular e progressista a frente da prefeitura do Recife, seu nome ficará, de algum modo, mais associado e estigmatizado pelos setores conservadores e retrógrados como um esquerdista ou mesmo comunista ${ }^{5}$. Tal estigma ficará mais explicito durante as disputas eleitorais para o governo do estado em 1962, quando parte da imprensa hegemônica local em conluio com segmentos religiosos, sobretudo, autoridades clericais da igreja católica desenvolveram forte campanha contra o perigo vermelho simbolizado na figura deste ator politico ${ }^{6}$.

\footnotetext{
${ }^{5}$ Vide CAVALCANTI, Paulo. O caso eu conto como o caso foi. De Prestes à queda de Miguel Arraes. Volume III, $3^{\circ}$ edição. Recife: Ed. CEPE, 2018

${ }^{6}$ Tal medo do perigo vermelho representado por Miguel Arraes à igreja Católica leva autoridades religiosas como o bispo da cidade de Caruaru, Dom Augusto Cardoso, a pedir aos fiéis para não votarem nele. Sobre isso vale a pena ver o trabalho de CAVALCANTI, Erinaldo. Ditadura Militar no Brasil entre práticas $\boldsymbol{e}$ representações (1960-1968). Recife: Ed. Universitária/UFPE/FGV, 2017
} 
Revista NEP - Núcleo de Estudos Paranaenses, Curitiba, v. 5, n. 2, dez. 2019

A ação politico-administrativa de Miguel Arraes, tanto à frente da prefeitura como do governo do estado, teve um caráter de fato democrático e popular, na medida em que buscou valorizar os diálogos e as demandas de alguns setores historicamente esquecidos e marginalizados pelos governos aliados às elites pernambucanas. Seu apoio ao Movimento de Cultura Popular (MCP) ligado a UNE e a um projeto de alfabetização desenvolvido por Paulo Freire e diversas reinvindicações de setores populares das comunidades periféricas do Recife, em parceria com forças politicas tradicionais de esquerda contribuiu para projetá-lo como um diferente das elites do PSD e da UDN. Vale salientar que no Recife já havia uma forte tradição de esquerda. O governo de Arraes havia sido precedido e beneficiado pelo também progressista e democrático governo de Pelópidas Silveira. Mas tal identidade se ampliará e ganhará contornos mais densos e fortes com o eclipsar dos anos 1960, que no Brasil, dar-se-ão com o aprofundamento das contradições de classes e o fortalecimento da consciência politica de operários, estudantes, artistas e camponeses. A Revolução Cubana (1959) elevará ainda mais tais tensões, uma vez que será usada pelas forças em disputa para justificar ações revolucionárias, golpes e a instituição de regimes autoritários na América Latina.

É nesta seara que ganha contornos dramáticos a luta pela reforma agraria, algo há muito tempo resolvido nas democracias ocidentais. Mas que no Brasil viceja como um grande tabu. A luta a favor e contra a reforma agrária mobilizou os mais distintos grupos e classes sociais. Em Pernambuco, o PCB, frações trotskistas, as ligas camponesas, os sindicatos rurais e setores da igreja católica disputavam sua influência junto aos camponeses e pequenos agricultores. A eleição de Arraes para o seu primeiro mandato como governador dá-se neste ambiente pulverizado por divergência e radicalismo dentro da própria esquerda ${ }^{7}$. E ele embora fosse apoiado por Cid Sampaio, governador ligado ao PSD e a figuras mais liberais da classe dominante, como o empresário José Ermírio de Moraes, assumirá com coragem a defesa de algumas destas bandeiras consideradas à época como radicais e perigosas à ordem social ${ }^{8}$. A sua proximidade e apoio às demandas populares numa sociedade tão desigual e violenta, transformaria, paradoxalmente, sua

\footnotetext{
${ }^{7}$ Vide ABREU e LIMA, Maria do Socorro. Construindo o sindicalismo rural. Lutas, partidos, projetos. Recife: Ed. Universitária/UFPE,2012.

${ }^{8}$ Sobre a curta experiência, porém, impactante do primeiro governo Miguel Arraes, vide a obra de CALlADO, Antonio. Tempo de Arraes. A Revolução sem violência. 2 edição. Rio de janeiro: Paz e Terra, 1979.
} 
imagem pública numa espécie de Janus, uma figura bifronte, associada por uns ao bem e por outros ao mal. Da sua relação com aquilo que seria visto como o "mal comunista", arcará com a violência de ter sido um dos primeiros políticos a perder o mandato e a ser preso em função do golpe civil-militar de 1964.

Contudo, Miguel Arraes nunca fora um radical, revolucionário ou defensor intransigente das reformas sociais Era um nacionalista da esquerda democrática. Portanto, mais sensível ao pragmatismo no que tange a fazer alianças e concessões a setores das elites e da direita, porém, sem abdicar essencialmente do comando e das suas convicções ideológicas. Mas, mesmo assim, fora estigmatizado e combatido pelos setores conservadores e reacionários das classes médias, das alas da igreja católica, da imprensa e das elites como um grande inimigo da família, da pátria e da propriedade.

Para se compreender a construção da sua imagem emblemática, precisamos observar que não se trata de um ator localizado num dado tempo, preso a único acontecimento, mas de alguém cuja atuação atravessou diferentes momentos da história republicana do país. Alguém que vivenciou o apogeu e a queda do nacionaldesenvolvimentismo, a ruptura e os efeitos produzidos pelo golpe e a ditadura civilmilitar e a chamada Nova República, com qual a partir de conquistas e derrotas passaria a se constituir na maior liderança das esquerdas e setores progressistas pernambucanos, responsável por derrotar por três vezes a direita tradicional que, desde o golpe até 1986 hegemonizava a politica estadual. Em todos esses momentos, direta ou indiretamente, seu nome não cessou de ecoar na memória social e política como um espectro vivo e reluzente.

Mesmo após a redemocratização, a imagem pública de Arraes manterá seu caráter bifronte. E, como sempre, sofrerá ataques e constantes abalos. O escândalo dos precatórios ${ }^{9}$ envolvendo a ele e seu neto, o então secretário da fazenda Eduardo Campos, durante seu terceiro governo (1995-1998), contribuiria para o enfraquecimento do seu mito, levando-o a uma fragorosa derrota para Jarbas Vasconcelos, seu antigo aliado, quando tentava conquistar seu quarto mandato nas eleições de 1998. As pesquisas mostraram sua alta taxa de rejeição e reduzida intenção de voto, porém, mesmo assim, ele topou o auto sacrifício com o objetivo de fazer a defesa do seu capital simbólico e do

\footnotetext{
${ }^{9}$ https://www.folhadelondrina.com.br/politica/depois-da-crise-arraes-recupera-imagem-55701.html
} 
seu neto, o mais atacado pelas oposições e a imprensa. O mito Arraes configura-se, pois, numa longa história de sucessivas vitórias e derrotas, esperanças e sofrimentos, avanços e recuos, alianças com setores populares e conciliações com segmentos da direita e das classes dominantes. Tais aspectos revelam-nos, ao mesmo tempo, a força e os limites do seu espectro politico e familiar.

Devido à riqueza e a singularidade da sua vida e história de homem público, Arraes tornou-se portador de uma força carismática e mobilizadora de esperanças e utopias para seus aliados e eleitores. Suas campanhas eleitorais se caracterizavam por agenciar a criatividade e o talento de artistas, músicos, intelectuais e estudantes que por meio de "brigadas muralistas"10 produziam mensagens politicas nos muros das cidades, ao estilo dos pintores mexicanos Diego Rivera e Siqueiros, além de canções de forte impacto psicológico, como "Ele está voltando", hino da campanha de 1986, que fazia alusão a sua volta do exílio, e emitia um conjunto de signos voltados à esperança de dias melhores. Esses mesmos signos eram reforçados pelas fotos emblemáticas de um homem com um charuto na boca e um sorriso no olhar, apresentando-se como uma espécie de Moisés ${ }^{11}$, aquele que conduzirá o povo no caminho da liberdade e da justiça.

Tais representações têm ajudado a colocá-lo numa posição de destaque na História recente do pais. A sua identidade politica inscreve-se naquilo que historiadores como Jorge Ferreira e Daniel Aarão Reis denominam de nacionalismo e reformismo radical ${ }^{12}$. Trata-se de políticos que a despeito de suas filiações ao nacionalismo de viés getulista, trabalhista e militar, tinham posições fortes e combativas em defesa da soberania nacional, da ampliação dos avanços democráticos e da justiça social. Talvez seja por esses motivos que ele tenha sido homenageado pela Escola de Samba Unidos da Vila Isabel no carnaval de 2016, e inscrito em 2019 no seleto Livro dos Heróis e Heroínas Brasileiros também chamado Livro de Aço ${ }^{13}$.

\footnotetext{
${ }^{10}$ Vide REMIGIO, Elizabeth. As brigas muralistas e as campanhas de Arraes. Arte e politica na década de 1980. Recife: Ed. CEPE, 2016.

${ }^{11}$ Vide. GIRARDET, Raoul. Mitos e mitologias Politicas. São Paulo: Cia. das Letras, 1987.

${ }^{12}$ Vide REIS, Daniel Aarão, FERREIRA, Jorge. (Orgs.) Nacionalismo e Reformismo Radical. (19451964). Rio de Janeiro: Rio de Janeiro: Civilização Brasileira, 2007.

${ }^{13}$ https Vide. GIRARDET, Raoul. Mitos e mitologias Politicas. São Paulo: Cia. das Letras, 1987.

13 Vide://www.folhape.com.br/politica/politica/politica/2018/12/12/BLG,8887,7,547,POLITICA,2419MIGUEL-ARRAES-HEROI-PATRIA.aspX
} 
Como estrategista, ele percebeu que o elitismo e conservadorismo da politica estadual presente não apenas nas classes dominantes como também nas próprias camadas populares, não seriam rompidos com alianças exclusivas com as forças progressistas ou de esquerda. Para se chegar até às áreas mais distantes dos grandes centros urbanos era preciso estabelecer alianças com algumas famílias politicas destas localidades. Portanto, por meio de alianças com lideranças locais e conservadoras, muitas delas advindas da ARENA e PDS, e moldadas pelas práticas do nepotismo, clientelismo e mandonismo. Com o apoio de algumas destas famílias e oligarquias politicas, o espectro Arraes se deslocará da região metropolitana do Recife para as médias e pequenas cidades, vilas e sítios do interior pernambucano. As famílias Galvão ${ }^{14}$, na zona do agreste, e uma parte da legendária família Coelho ${ }^{15}$, no sertão, exemplificam bem esta expansão do espectro arraesista, o que por sua vez irá facilitar a entrada também de outras forças politicas e sociais progressistas. A vitória de Lula no segundo turno das eleições presidenciais de 1989 em Pernambuco, apesar da votação expressiva na capital prescindiu significativamente dos votos daquelas regiões, outrora totalmente refratárias às forças democráticas e populares.

Nestas paisagens que historicamente se caracterizavam por profundas desigualdades sociais e a quase completa ausência de signos modernos, a figura de Arraes, no plano estadual, assemelha-se a de Vargas no plano nacional. Ou seja, como uma espécie de "pai dos pobres" habitantes das localidades mais esquecidas e sofridas do campo.

Para os pequenos agricultores e camponeses, moradores das referidas regiões, seu valor e reconhecimento advêm principalmente do amplo trabalho de eletrificação rural que realizou a partir do seu segundo governo (1987-1990), do financiamento para compra de gado bovino, bem como do apoio às lutas políticas em favor da reforma agrária, da sindicalização, da formalização do trabalho no campo e da extensão do salário mínimo

\footnotetext{
${ }^{14}$ Vide ADILSON FILHO, José. A cidade Atravessada. Velhos e novos cenários na politica belojardinense. Recife: Comunigraf, 2009.

${ }^{15}$ SANTOS, Ruiter Antônio Bezerra dos. Nas sobras da familia Coelho: A dinâmica de uma dominação politica. Tese de doutorado defendida no Programa de Pós-graduação em Ciências Sociais da Universidade Federal do Rio Grande do Norte: 2013. https://repositorio.ufrn.br/jspui/bitstream/123456789/13830/1/SombrasFam\%c3\%adliaCoelho_Santos 20 13.pdf
} 
(1963-1964), de programas de alfabetização popular baseados no Método Paulo Freire ${ }^{16}$, ou através de programas como o Chapéu de Palha, voltado para complementar à renda dos trabalhadores da área açucareira quando ficavam temporariamente desempregados durante o período da entressafra.

Com a redemocratização Miguel Arraes se elegera duas vezes governador de Pernambuco, a primeira pelo PMDB, em 1986, numa frente popular que reunia velhas lideranças do chamado MDB autêntico, como Jarbas Vasconcelos, Marcos freire e Fernando Lyra, tendo Carlos Wilson, ex-membro da direita, como seu vice. Já a segunda vitória, em 1994, fora conquistada pelo PSB, como efeito do rompimento com o PMDB. Nesta disputa, a chamada Frente Popular ficaria menor, mas seria composta de partidos de esquerda e centro-esquerda como o PT, PC do B, e PPS. E também por duas vezes elegera-se deputado federal (1990 e 2002). Nas disputas de 1990, foi um dos mais votados do Brasil, ajudando a eleger cinco deputados federais numa chapa que reunia PSB e PCdoB, e por muitos anos presidiu o partido socialista brasileiro, que passou a figurar como uma agremiação cada vez mais estratégica na correlação das forças estaduais, principalmente na região Nordeste. No plano nacional contribuiu para a vitória de Lula no segundo turno das eleições presidenciais de 2002, da qual resultaria a indicação de Eduardo Campos para o Ministério da Ciência e Tecnologia. Ele morreria no dia 13 de agosto de 2005, aos 88 anos, quando exercia seu segundo mandato de deputado federal, deixando profundas marcas na historia e na memória pernambucana e nacional. Seu legado, claro, seria reivindicado e disputado por seus familiares, amigos e correligionários.

\section{Agora é a vez do neto: Eduardo Campos e a construção de uma nova hegemonia politica de base familiar}

Apesar da grande prole (dez filhos e filhas resultantes de dois casamentos) os Arraes durante muito tempo não se constituíram como uma família politica ou mesmo uma oligarquia. Trata-se de uma família que de 1940 até meados de 1980, tivera em Miguel Arraes, ou seja, num único sujeito o exercício efetivo da politica, caso pensemo-

\footnotetext{
${ }^{16}$ Vide CALADO, Antônio. Obra já citada.
} 
lo em termos de lideranças, mandatos e ocupações de cargos estratégicos na burocracia estatal. De 1948 até 1987, como vimos, falamos de um ator que assumira os cargos de secretário da fazenda, deputado estadual, deputado federal, prefeito, governador, sem, entretanto, fazer nenhuma referência a outro membro do clã. Com raras exceções, a exemplo de Luís Carlos Prestes, Lula e alguns outros são práticas comuns à cultura politica brasileira as lideranças ou chefes inserirem ainda muito cedo no âmbito da maquinaria partidária e estatal, os filhos e demais parentes com vistas à constituição de hegemonias de base familiar.

Com os Arraes essa prática que transforma a "politica como negócio de família"17 levará quase meio século para começar a apresentar seus primeiros sinais. Tal situação inicia-se a partir do segundo governo, quando da nomeação de seu neto, Eduardo Henrique Accyoli Campos, um jovem de apenas 19 anos, para ocupar a função de chefe de gabinete. A partir daí o espectro de Eduardo Campos vai se tornando cada vez mais visível na esfera local como aquele que irá herdar o legado do avô. Note-se, portanto, que o neto não traz o sobrenome do avô nem da sua mãe Ana Arraes, mas do pai, Maximiano Campos, um importante escritor pernambucano, autor de 17 livros. No entanto, Campos não se identificará com o legado do pai, e sim com o do avô.

Porém, para a sua construção como futuro líder precisaria diferencia-se da figura mítica do avô. Tal singularidade seria elaborada por meio da fabricação da sua imagem como um jovem ator moderno, qualificado e competente para o exercício da politica. A sua formação como economista pela UFPE e a experiência como chefe de gabinete levou a criar a primeira Secretaria de Ciência e Tecnologia do estado e do nordeste bem como a Fundação de Amparo à Ciência e à Tecnologia do Estado de Pernambuco (FACEPE). Por meio desta atuação, caracterizada pela apropriação de tais signos, ele buscava se apresentar como um sujeito articulado com as demandas mais avançadas da modernidade brasileira. Enquanto o avô tinha sua imagem associada às politicas públicas de combate à pobreza e a promoção da cidadania, sobretudo, das comunidades rurais. Eduardo Campos queria a partir deste tipo de protagonismo impor a sua administração um viés mais racional e moderno.

\footnotetext{
${ }^{17}$ Sobre essa prática cultural e politica nacional, vide MONTEIRO, José Marciano. A Politica como
} Negócio de Família. Por uma sociologia politica das elites e do poder familiar. São Paulo: LiberArs, 2017. 
Em 1992, seria rompida a aliança entre Jarbas e Arraes, o que levaria Eduardo Campos a ser indicado candidato a prefeito do Recife naquele ano. Mas sua primeira disputa a uma eleição majoritária foi um verdadeiro fracasso ${ }^{18}$, pois ficara em quinto lugar em relação ao vencedor Jarbas Vasconcelos. Daí em diante, ele seria cada vez mais combatido pelos adversários que o viam como aquele que naturalmente ocuparia o lugar de um líder em fim de carreira.

A sua emergência como substituto de Arraes será contestada tanto à direita como à esquerda, já que antigos atores da frente popular e do partido dos trabalhadores constatavam sua liderança. E isso ficará mais visível com o escândalo dos precatórios durante sua passagem pela Secretaria da Fazenda (1995-1998), após seu desligamento da câmara federal. A despeito de ter sido eleito o deputado federal mais votado nas eleições de 1998, recaia sobre Campos o fardo da derrota humilhante sofrida pela chapa encabeçada pelo avó ao governo do estado. Parte deste mandato fora usado para defender a si próprio e a Arraes na CPI que investigava o referido escândalo. Alguns anos depois ambos seriam inocentados pelo Supremo Tribunal Federal.

Os ventos começaram a soprar com a vitória dos dois para deputado federal e de Lula para presidente nas eleições de 2002. Pode-se afirmar que a partir deste momento o rosto de Eduardo Campos ganhou um novo brilho. Os movimentos da "onda vermelha" ajudaram a oxigenar e a fortalecer o nome e o papel politico de Campos, tanto em nível estadual como nacional. Sua boa atuação no Ministério da Ciência e Tecnologia no debate sobre o uso das células-tronco ${ }^{19}$ e outros temas importantes lapidou sua imagem como um ator competente e qualificado, trazendo-o de volta à disputa pela condição de futura liderança da chamada Frente Popular. Mas isso começaria a se efetivar após a morte de Miguel Arraes (2005) e sua eleição para governador um ano depois.

A sua vitória contra José Mendonça Filho (DEM), candidato apoiado por Jarbas Vasconcelos, no segundo turno, por mais de sessenta por cento dos votos válidos ${ }^{20}$, representou para ele e antigos aliados a desforra em relação à derrota sofrida por Arraes. Apesar do uso sistemático da memória politica do avô, já falecido, do qual soube nutrir-

\footnotetext{
${ }^{18} \mathrm{http} / / / \mathrm{www} \cdot$ tre-pe.jus.br/eleicoes/eleicoes-anteriores/eleicoes-1992/divulgacao-de-resultados-1992

${ }_{19}$ https://pib.socioambiental.org/es/Not\%C3\%ADcias?id=36624

${ }^{20} \mathrm{http} / / / \mathrm{www}$. tre-pe.jus.br/eleicoes/eleicoes-anteriores/eleicoes-2006-1/eleicoes-2006
} 
se para a legitimação do seu nome, ele tivera que contar com o apoio decisivo de duas novas forças estratégicas para sua vitória consagradora: Lula e o PT.

A junção destes elementos levou-o, por duas vezes, ao Palácio do Campo das Princesas (sede do governo). Em pouco tempo, esse sobrenome será mais reluzente do que o de Arraes. Pois, conforme os olhos da maioria da sociedade pernambucana a sequência Arraes/Campos seria trocada por Campos/Arraes. O neto com a sua expressiva popularidade encapsulava o mito do avô, ao mesmo instante em que o homenageava através da construção de diversos lugares de memória com o seu nome ${ }^{21}$, a exemplo de hospitais, escolas, praças, institutos, sede de partido, etc.

As duas administrações de Eduardo Campos (2007-2010, 2011-2014) buscaram, como já foi dito, esculpir a sua imagem como um politico moderno, eficiente e sensível ás demandas da sociedade, sobretudo, às relativas à educação, segurança e tecnologia. Programas voltados para a redução da violência Como Pacto Pela Vida ${ }^{22}$ ou de valorização dos professores mediante o pagamento de um $14^{\circ}$ salário em função de metas a serem atingidas pelas unidades escolares no que tange à melhoria na qualidade do ensino e na redução da evasão escolar bem como a criação e expansão das escolas de referência no ensino médio (EREM) ${ }^{23}$ e nas escolas técnicas estaduais (ETE), ambas de tempo integralizado, o que parece ter sortido efeitos positivos do ponto de vista da avaliação da sua concepção e execução por parte de vários segmentos sociais. Tais resultados seriam sempre usados por ele e seus aliados como o governador Paulo câmara - sua criatura politica - como importante instrumento de marketing eleitoral, algo inclusive usado por aliados no plano nacional a exemplo de Marina Silva (REDE) e Fernando Haddad (PT) Contudo, seus críticos mais qualificados, isto é, alguns professores e pesquisadores, veriam tais ações e resultados como produtos de uma perspectiva empresarial ${ }^{24}$ e até

\footnotetext{
${ }^{21} \mathrm{https}: / / w w w . l e i a j a . c o m / p o l i t i c a / 2017 / 05 / 31 /$ duardo-campos-ja-batiza-mais-de-10-obras-e-orgaos/ 22 https://suellany.jusbrasil.com.br/artigos/655348876/reflexoes-sobre-o-programa-pacto-pela-vidapernambuco

${ }^{23}$ https://www.institutounibanco.org.br/aprendizagem-em-foco/47/

${ }^{24}$ SANTIAGO, Frederico Márcio Leandro. Educação e Desenvolvimento em Pernambuco entre 2004 e 2014. Desvelando os nexos entre o Programa Educação de Tempo Integral e o rejuvenescimento da teoria do capital Humano. Dissertação de mestrado defendida no Programade Pós-graduação em educação da Universidade federal de Pernambuco- Campus do Agreste, em 23 de setembro de 2014. Para acessá-la: https://attena.ufpe.br/bitstream/123456789/15100/1/Disserta\%C3\%A7\%C3\%A3o\%20final\%20PDF\%203 .pdf
} 
mesmo neoliberal para a educação ${ }^{25}$. Algo semelhante à gestão de Aécio Neves (PSDB) no governo de Minas Gerais.

O fato é que Eduardo Campos fora avaliado por vários institutos de pesquisa como o governador mais popular do Brasil. E isso se deve também a sua capacidade administrativa. Mas por trás desta história de sucesso que o levou à reeleição ao derrotar Jarbas Vasconcelos, seu principal adversário, com a diferença acachapante de quase oitenta e três por cento dos votos válidos ${ }^{26}$ dos votos válidos, vale ressaltar o papel do também excelente desempenho do segundo governo Lula, cuja popularidade atingia níveis altíssimos. Lula, pelo fato de ser pernambucano e pelas antigas afinidades pessoais com o clã Arraes/Campos, investiu significativamente em obras e recursos para o estado. O resultado desta parceria levou o estado de Pernambuco a apresentar as maiores taxas de crescimento econômico do país durante este período.

Vale frisar que além dos bons resultados advindos desta parceria, o governo de Eduardo Campos, de certa forma, neutralizou e limitou ao máximo os efeitos negativos do seu governo e das críticas, visto que contou com o apoio da grande impressa local (TVs, jornais impressos e rádios), sem esquecer que em boa parte dos municípios pernambucanos gozava de alianças e do apoio das principais forças politicas. Na sua campanha para reeleição era comum em muitas cidades haver dois grupos políticos lutando por seu apoio. Algo semelhante ao que acontecia com Lula, quando se viam prefeitos e candidatos das mais variadas tendências partidárias surfando na onda da sua popularidade.

Nas eleições municipais de 2012, ele elegera a maioria dos candidatos a vereador e a prefeito, inclusive os do Recife, a capital, que há 12 anos estava sob o domínio de prefeitos petistas. Agora com um capital politico ampliado e legitimado popularmente, passaria a almejar voos mais altos. Porém, isso dependeria do seu rompimento e do PSB com o governo de Dilma Rousseff, seguido do seu lançamento como candidato nas eleições presidenciais de 2014, numa chapa que contaria com Marina Silva como vice.

\footnotetext{
${ }^{25}$ BENITTES, Valéria de Lima Andrioni. A politica do ensino médio no estado de Pernambuco:Um protótipo da gestão em educação de tempo integral. Dissertação de mestrado defendida no Programa de Pós-Graduação em Educação da Universidade federal de Caruaru- Campus do Agreste - Caruaru, em 12 de setembro de 2014. Para acessá-la segue o link: https://repositorio.ufpe.br/bitstream/123456789/11301/1/DISSERTA\%C3\%87\%C3\%83O $\% 20 \mathrm{Val} \% \mathrm{C} 3 \%$ A9ria\%20Lima\%20Benittes.pdf

${ }^{26} \mathrm{http}$ ://www.tre-pe.jus.br/eleicoes/eleicoes-anteriores/eleicoes-2010-1/consultas-de-resultado
} 
Revista NEP - Núcleo de Estudos Paranaenses, Curitiba, v. 5, n. 2, dez. 2019

\section{O espetáculo da morte de Eduardo Campos e os seus herdeiros políticos.}

Em 13 de agosto de 2014, Eduardo Campos e mais alguns assessores são vitimas fatais de um acidente aéreo sobre um bairro da cidade de Santos (SP). Por coincidência, Miguel Arraes, morrera nesta mesma data nove anos antes. Independentemente de suas filiações partidárias, a morte trágica de um líder politico produz fortes impactos psicológicos sobre os mais variados sujeitos. A morte tem essa força de suavizar as tensões e juntar momentânea e ritualisticamente os adversários.

No velório de Eduardo Campos, na frente do Palácio do Campo das Princesas, viam-se além de milhares de eleitores, admiradores e curiosos, centenas de políticos de várias tendências ideológicas, como a presidente Dilma Rousseff, o ex-presidente Lula, Ciro Gomes, Aécio Neves, Roberto Freire, Marina Silva, ACM Neto, entre outros. Aquela morte trágica, todavia, acontecera durante uma acirradíssima disputa presidencial, na qual Campos despontava como uma alternativa a polarização produzida pelo PT e o PSDB.

Portanto, sua morte adquiriria dimensões espetaculares, visto que nela misturavam-se estrategicamente interesses políticos, econômicos e midiáticos para serem usados contra a reeleição de Dilma Rousseff, que será amplamente atacada por aliados e eleitores por meio das redes sociais, de pichações de muros ou em discursos em que as responsabilizavam pela tragédia que o levou a morte.. Durante o velório, por diversas vezes, ela fora vaiada por aliados e correligionários da família Campos. Violência simbólica que neste momento era produzida pelo PSB, antigo aliado de Lula e do PT, que um ano depois passaria a conspirar ativamente a favor do golpe parlamentar que levou a queda da presidente petista.

A cobertura da tragédia, do velório e do enterro foi feita de forma intensa e duradoura por um batalhão de jornalistas, comentaristas, políticos e repórteres da Rede Globo, SBT, Record, Band e outros, que de certa maneira buscavam não apenas noticiar e analisar o evento, mas mitificar a figura de Eduardo Campos. Este acontecimento midiático, em termos de ressonância e impacto social e psíquico só perderia proporcionalmente para as mortes de Getúlio Vargas e Tancredo Neves.

No Brasil contemporâneo, os velórios de políticos, desportistas e celebridades ao serem espetacularizados revelam aspectos da cultura brasileira ${ }^{27}$, no que tange a forma

\footnotetext{
${ }^{27}$ MARCELINO, Douglas Átilla. O corpo da Nova República. Rio de Janeiro: FGV, 2016.
} 
teatralizada como os cidadão e fãs expressam seus sentimentos, suas emoções e paixões. E numa sociedade cada vez mais dominada pelo signo do espetáculo ${ }^{28}$, a legitimidade, a permanência e a consagração do ator político passam pela mediação da economia das imagens e dos discursos. Daí ser necessário ao pesquisador procurar questionar os dispositivos que produzem tais evidências no olhar.

A imagem pública de Eduardo Campos será inflacionada e apropriada pela família (mulher, filhos, mãe, irmãos) e por aliados como Paulo Câmara, atual governador de Pernambuco, e Marina Silva, que de forma bizarra fazia selfies com cidadãos ao lado do caixão $^{29}$. Para ambos, o espectro do morto contribuirá positivamente. Enquanto Paulo Câmara seria eleito governador no primeiro turno das eleições estaduais, Marina Silva em menos de uma semana ultrapassava nas pesquisas Aécio Neves e empatava com Dilma Rousseff, porém, não foi o suficiente para levá-la a vitória.

Mesmo após a morte do líder, a família Campos se manteria forte. Renata Campos, sua esposa, ocuparia um papel destacado nesta hegemonia, uma vez que as indicações de alguns cargos na burocracia municipal e estadual, assim como apoio a candidatos a prefeito e a governador ou possíveis alianças nacionais prescindiria do seu aval. Sua casa tornou-se ponto de visitação constante para os mais diversos políticos do país. A família não demorou em fabricar ${ }^{30}$ o futuro "príncipe" do estado. O governador Paulo Câmara nomearia o primogênito João Campos para chefe de gabinete (2015), a mesma função que o pai ocupara quando da sua iniciação pela vida politica institucional.

Três anos depois, agora nas eleições de 2018, o jovem João Campos igualmente ao pai, a avó e ao bisavô era eleito o deputado federal mais votado do estado ${ }^{31}$. Os quase quinhentos mil votos obtidos resultam não apenas da força espectral do pai, mas também do uso da máquina administrativa e partidária. De posse de ambos, certamente será indicado como candidato a prefeito do Recife (2020) ou a governador no pleito de 2022. Quanto aos quatro irmãos ainda precisam amadurecer, pois. são muito jovens. Mas como

\footnotetext{
${ }^{28}$ Vide DEBORD, Guy. A sociedade do espetáculo. Rio de janeiro: Paz e Terra, 1997.

${ }^{29} \mathrm{https}$ ://vejasp.abril.com.br/cidades/autorretratos-velorio-eduardo-campos/

${ }^{30}$ Essa ideia de fabricação ou construção da imagem pública do ator politica foi trazida das contribuições de BURKE, Peter. A fabricação do rei. A construção da imagem pública de Luís XIV. Rio de Janeiro: Jorge Zahar, 2012.

${ }^{31}$ A eleição consagradora do jovem representava a continuidade e perpetuação da nova oligarquia no poder, de viés de centro-esquerda. Para mais informações, vale apena acessar: https://brasil.elpais.com/brasil/2018/10/10/politica/1539200181_132029.html
} 
é comum na lógica das famílias politicas, é bem possível que alguns desses já estejam sendo preparados e lapidados para participar dos jogos de poder e da maquinaria estatal.

Já os outros membros da família ocupam posições atualmente estratégicas nas engrenagens do estado em nível federal. Ana Arraes, a mãe de Eduardo, após ser eleita por duas vezes deputado federal pelo PSB, a partir de 2011 passa a ocupar o cargo de ministra do Tribunal de Contas da União (TCU), enquanto seu filho, o advogado e escritor Antonio Campos, conhecido como Tonca, na contramão do alinhamento politico da família, seria nomeado presidente da Fundação Joaquim Nabuco (FUNDAJ), instituição de pesquisa ligada ao Ministério da Educação (MEC) pelo governo de Jair Bolsonaro. Ele fora candidato derrotado à prefeitura de Olinda pelo professor Lupércio (SD). A razão desta derrota é atribuída à falta de apoio de Paulo Câmara e de Renata Campos.

Tonca, como é conhecido, se diz inconformado com a falta de apoio da legenda e de parentes na campanha. Disparou críticas a todos, inclusive a Renata Campos, viúva do ex-governador de Pernambuco, morto em um acidente aéreo em 2014. À Folha, referiu-se à ex-cunhada como "ingrata" e a acusou de fazer indicações nos quadros nos Executivos do Recife e de Pernambuco. "Ela deveria explicar a quantidade de cargos que tem nos governos estadual e na prefeitura", disse Tonca. ${ }^{32}$

Como havíamos dito antes, Renata Campos, mulher de Eduardo Campos, economista e auditora do Tribunal de Contas do Estado de Pernambuco (TCE), passaria a exercer forte influência sobre as administrações de Geraldo Júlio (prefeito do Recife) e Paulo Câmara. Tal influencia conforme o depoimento passional dele sugere que sua candidatura fora inviabilizada para alijá-lo como possível herdeiro do legado do clã Campos/Arraes. O outro racha dera-se a partir de Marilia Arraes, neta de Miguel Arraes e prima em primeiro grau de Eduardo, após este e o PSB romperem a aliança com o PT e o governo de Dilma Rousseff.

A então vereadora do Recife se desfilaria do PSB e ingressaria no PT num momento muito difícil para esse partido na conjuntura nacional. A partir daí essa jovem mulher teria um importante protagonismo na renovação das esquerdas e se projetaria como forte herdeiro do legado de Miguel Arraes. Ao contrário dos Campos ela traz consigo o sobrenome histórico do avô. E como nos mostra Bourdieu, a apropriação de

32 https://www1.folha.uol.com.br/poder/eleicoes-2016/2016/11/1829176-derrotado-em-olinda-irmao-deeduardo-campos-ataca-viuva-e-partido.shtml 
um determinado sobrenome é fundamental para ampliação do capital politico e simbólico daqueles que buscam identifica-se com ele e perpetuá-10 ${ }^{33}$. A vinculação a este sobrenome rendeu a Marilia Arraes a simpatia e o reconhecimento de vários segmentos sociais. E isto seria ampliado ainda mais com a força e carisma popular de Lula, a maior liderança do país. Marilia, criativamente, colou o máximo a sua imagem a de Arraes e de Lula para se fortalecer dentro e fora do PT como uma alternativa viável a velha polarização politica do estado.

Seu nome empolgou e mobilizou a militância do partido e ampla parcela dos cidadãos pernambucanos, a ponto de por várias vezes se colocar na frente das pesquisas majoritárias para governador do estado nas eleições de 2018. Mas devido aos interesses estratégicos do diretório nacional do PT, ela foi obrigada a desistir da candidatura em prol da aliança com Paulo Câmara e disputar uma vaga à câmara federal, onde seria a segunda mais votada, com quase duzentos mil votos. Ela e o primo João Campos seriam os mais votados do estado à câmara federal, e, também, se transformariam em dois fortes concorrentes às próximas eleições para prefeito do Recife e para o governo do estado.

Com a emergência e consolidação de João Campos e de Marília Arraes na politica estadual, fortalece-se, de modo ambivalente, a força e a permanência do clã ArraesCampos como uma das famílias mais emblemáticas e influentes da história local e nacional, a partir de meados do século XX.

\section{A família Arraes/campos: uma oligarquia em construção}

A história brasileira desde suas origens até os dias atuais continua sendo marcada pela presença fantasmagórica e ostensiva de algumas famílias nas suas múltiplas dimensões. É, entretanto, nas esferas da politica e da economia que sua força se faz mais presente. Assim, não há como deixar de perceber esse elemento marcante na nossa formação histórica, e de como ele constitui-se, na maioria das vezes, num enorme obstáculo para os avanços da cidadania, da justiça e da democracia.

Não há, pois, como pensar nesse país sem deixar de problematizar a força desconcertante deste velho signo e emblema da nossa história, cujo poder se faz onipresente em todas as suas localidades e regiões. Vale salientar que nessas famílias

\footnotetext{
${ }^{33}$ BOURDIEU, Pierre. O poder simbólico. Rio de Janeiro: Bertrand Brasil, 2001.
} 
prevalece predominantemente um ethos conservador e, reacionário, advindos de suas origens aristocráticas, burguesas e de classe média. Raramente encontram-se nelas uma fração que seja proveniente do campesinato ou do proletariado urbano, ou mesmo que se identificam ideologicamente com as ideias mais progressistas ou radicais..

A sociedade pernambucana não foge à regra, pois desde sua longa história fora encapsulada por esse tipo de relação de poder. No império ficou famosa a frase na qual se dizia que em Pernambuco "ou se é Cavalcanti ou se é cavalgado", devido ao poder quase onipotente desta família aristocrática na vida econômica e politica da província. Já na República, tal realidade fica mais dinâmica e plural, pois contemplará diversos clãs e algumas figuras politicas nascidas das camadas médias e com perfis mais liberais e nacionalistas.

Os Arraes/Campos inscrevem-se numa tradição diferente, pois se trata de atores sociais advindos da classe média rural e urbana, composta por advogados, economistas, engenheiros, intelectuais e artistas, com uma história e identidade politico-ideológica mais próxima do espectro de esquerda. A maioria deles ocupará funções e posições privilegiadas na burocracia estatal. A vida politica de Miguel Arraes e de Eduardo Campos ganha projeção a partir de funções desenvolvidas nesta esfera.

Como todos aqueles que conquistaram o poder no Brasil e buscaram exercê-lo durante certo tempo, os Arraes/Campos - como já foi enfatizado - precisaram fazer acordos e alianças com algumas famílias e oligarquias do estado, a exemplo dos Coelho, dos Galvão, dos Monteiro, dos Lyra, dos Farias, etc. Uma vez que sem a contribuição delas seria muito difícil adentrar-se em áreas da zona da mata, do agreste e do sertão, consideradas mais hostis aos políticos mais progressistas.

Com a chegada de Eduardo Campos ao governo do Estado, começa a se desenhar de forma mais nítida um projeto de poder para o clã. Alguns dos seus parentes irão ocupar lugares de poder e prestigio na esfera pública e privada. Já alguns dos seus mais fiéis aliados, vindos da burocracia, tornar-se-ão suas opções politicas para governar a capital e o estado, a exemplo de Geraldo Júlio e Paulo Câmara, já que tais indivíduos seriam mais fáceis de serem controlados do que políticos tradicionais, que mais tarde poderiam romper relações e prejudicar duplamente seus interesses regional e nacional.

Após a sua morte, restam os parentes mais próximos para dar continuidade ou não ao projeto politico familiar. Esta tarefa será no plano dos Campos exercida pela atuação 
forte de Renata Campos, viúva, que assumirá protagonismo fundamental na construção das alianças politicas, das escolhas de candidatos e indicações de nomes a composição de cargos de confiança do governo do estado e da capital. Será ela quem vai indicar o primogênito João Campos para chefe de gabinete, como balão de ensaio para voos maiores na vida politica. Os demais filhos por ainda serem demasiados jovens ficam por hora num certo anonimato até emergirem as condições adequadas.

Atualmente, os Campos/Arraes, aqui me refiro aos primos João Campos e Marília Arraes tendem a polarizar a politica pernambucana, o que conscientemente ou não, coloca a hegemonia tanto na situação quanto na oposição do espectro de praticamente uma só família. Baseado no que hoje se apresenta a partir dos vários espaços de poder que eles ocupam em nível local, regional e nacional, podemos afirmar que esta família passa a se constituir como uma oligarquia em construção, independentemente de sua origem e perfil mais democrático e progressista. Já que tende a reproduzir a mesma lógica elitista, desigual e conservadora das famílias tradicionais no que tange a apropriação e conservação dos capitais políticos, social e simbólicos, como estratégia fundamental para manter o poder sob o comando dos membros que justapõe o mesmo sangue com os mesmos sobrenomes.

\section{REFERÊNCIAS BIBLIOGRÁFICAS}

ABREU e LIMA, Maria do Socorro. Construindo o sindicalismo rural. Lutas, partidos, projetos. Recife: Ed. Universitária/UFPE, 2012.

ADILSON FILHO, José. A cidade Atravessada. Velhos e Novos cenários na política belojardinense. Recife: Comunigraf, 2009.

ANDRADE, Carlos Drummond de. Mãos dadas. In. Sentimento do Mundo. Cia das Letras: São Paulo, 2012.

BENITTES, Valéria de Lima Andrioni. A politica do ensino médio no estado de Pernambuco: Um protótipo da gestão em educação de tempo integral. Dissertação de mestrado defendida no Programa de Pós-Graduação em Educação da Universidade federal de Caruaru- Campus do Agreste - Caruaru, em 12 de setembro de 2014. Disponível 30\%20Val\%C3\%A9ria\%20Lima\%20Benittes.pdf>. Acesso em: 18 out. 2019. 
BOURDIEU, Pierre. O poder simbólico. Rio de Janeiro: Bertrand Brasil, 2001.

BURKE, Peter. A fabricação de Luís XIV. A construção pública da imagem de Luís XIV. Rio de Janeiro: Jorge Zahar Editor, 2012.

CALLADO, Antonio. Tempo de Arraes. A Revolução sem violência. 2 edição. Rio de Janeiro: Paz e Terra, 1979.

CAVALCANTI, Erinaldo. Ditadura Militar no Brasil entre práticas e representações(1960-1968). Recife: Ed. Universitária/UFPE/FGV, 2017.

CAVALCANTI, Paulo. O caso eu conto como o caso foi. De Prestes à queda de Miguel Arraes. Volum III, \$ edição. Recife: Ed. CEPE, 2018.

CHAVEAU, A, TETART, Phillippe.(orgs.) Questões para o Presente. Bauru: Edusc, 2000.

DEBBORD, Guy. A sociedade do espetáculo. Rio de Janeiro: Paz e Terra, 1997.

GIRARDET, Raoul. Mitos e mitologias políticas. São Paulo: Cia. das Letras, 1987.

MARCELINO, Douglas Atilla. O corpo da Nova República. Rio de Janeiro: FGV, 2016.

MONTEIRO, José Marciano. A Politica como Negócio de Família. Por uma sociologia politica das elites e do poder familiar. São Paulo: LiberArs, 2017.

REIS, Daniel Aarão, FERREIRA, Jorge. (Orgs.) Nacionalismo e Reformismo Radical. (1945-1964). Rio de Janeiro: Rio de Janeiro: Civilização Brasileira, 2007.

REMIGIO, Elizabeth. As brigas muralistas e as campanhas de Arraes. Arte e politica na década de 1980. Recife: Ed. CEPE, 2016.

RÉMOND, René (org.). A Nova História Política. Rio de Janeiro: FGV, 1996.

SANTIAGO, Frederico Márcio Leandro. Educação e Desenvolvimento em Pernambuco entre 2004 e 2014. Desvelando os nexos entre o Programa Educação de Tempo Integral e o rejuvenescimento da teoria do capital Humano. Dissertação de mestrado defendida no Programade Pós-graduação em educação da Universidade federal de Pernambuco- Campus do Agreste, em 23 de setembro de 2014. Disponível em: < https://attena.ufpe.br/bitstream/123456789/15100/1/Disserta\%C3\%A7\%C3\%A3o\%20fi nal\%20PDF\%203.pdf >. Acesso em: 18 out. 2019.

SANTOS, Ruiter Antônio Bezerra dos. Nas sobras da família Coelho: A dinâmica de uma dominação politica. Tese de doutorado defendida no Programa de Pós-graduação em Ciências Sociais da Universidade Federal do Rio Grande do Norte: Natal, 2013. Disponível

em: 
N E P Revista NEP - Núcleo de Estudos Paranaenses, Curitiba, v. 5, n. 2, dez. 2019 Dossiê Oligarquias do Nordeste no Brasil ISSN: $2447-5548$

$<$ https://repositorio.ufrn.br/jspui/bitstream/123456789/13830/1/SombrasFam\%c3\%adlia Coelho_Santos_2013.pdf >. Acesso em: 18 out. 2019.

Recebido em: 30 out. 2019

Aceito em: 26 nov. 2019 